\title{
ON A CLASS OF FINITE GROUPS
}

\author{
J. W. WAMSLEY \\ (Received 27 November 1972, revised 10 April 1973) \\ Communicated by G. E. Wall
}

1.

Let $G$ be a finite $P$-group. Denote $\operatorname{dim} H^{1}\left(G, Z_{p}\right)$ by $d(G)$ and $\operatorname{dim} H^{2}\left(G, Z_{p}\right)$ by $r(G)$, then $d(G)$ is the minimal number of generators of $G$ and $G$ has a presentation

$$
G=F / R=\left\{x_{1}, \cdots, x_{d(G)} \mid R_{1}, \cdots, R_{m}\right\},
$$

where $F$ is free on $x_{1}, \cdots, x_{d(G)}$ and $R$ is the normal closure in $F$ of $R_{1}, \cdots, R_{m}$. We have always that $m \geqq r(G)=d(R /[F, R])$ and we say that $G$ belongs to a class, $\mathscr{G} p$, of the finite $p$-groups if $m=r(G)$. It is well known (see for example Johnson and Wamsley (1970)) that if $G$ and $H$ are finite $p$-groups then $r(G \times H)=$ $r(G)+r(H)+d(G) d(H)$ and hence $G, H \in \mathscr{G} p$ implies $G \times H \in \mathscr{G} p$, also it is shown in Wamsley (1972) that if $G$ is any finite $p$-group then there exists an $H \in \mathscr{G}_{p}$ such that $G \times H$ belongs to $\mathscr{G}_{p}$. Let $G^{1}=G$ and $G^{k}=G^{k-1} \times G$ then we show in this note that if $G$ is any finite $p$-group, there exists an integer $n(G)$, such that $G^{k} \in \mathscr{G} p$ for alal $k \geqq n(G)$.

2.

Let $G$ be a finite $p$-group of nilpotency class $c$, then $G$ has a presentation $G=F / R=\left\{x_{1}, \cdots, x_{d(G)} \mid R_{1}, \cdots, R_{r(G)}, S_{1}, \cdots, S_{t}\right\}$ where $S_{1}, \cdots, S_{t}$ are commutators of weight $c+2$. Define $b(G)$ to be the minimal $t$ such that $G$ has a presentation of the above form, then $G \in \omega p$ if and only if $b(G)=0$.

LEMMA. Suppose $H$ and $G$ are finite p-groups then

$$
b(G \times H) \leqq \max (b(G)-r(H), 0)+\max (b(H)-r(G), 0) .
$$

ProOF.

$$
\begin{aligned}
& G=\left\{x_{1}, \cdots, x_{d(G)} \mid R_{1}, \cdots, R_{r(G)}, S_{j}, 1 \leqq i \leqq d(G), 1 \leqq j \leqq b(G)\right\} \\
& H=\left\{x_{1}^{\prime}, \cdots, x_{d(H)}^{\prime} \mid R_{1}^{\prime}, \cdots, R_{r(H)}^{\prime}, S_{j}^{\prime}, 1 \leqq i \leqq d(H), 1 \leqq j \leqq b(H)\right\}
\end{aligned}
$$


Let $K$ be presented on generators $x_{1}, \cdots, x_{d(G)}, x_{1}^{\prime}, \cdots, x_{d(H)}^{\prime}$ with relators, $\left[x_{i}, x_{j}^{\prime}\right], R_{m} S_{m}^{\prime-1}, R_{n}^{\prime} S_{n}^{-1}, S_{n}^{\prime} / S_{v}$, where $1 \leqq i \leqq d(G), 1 \leqq j \leqq d(H), 1 \leqq m \leqq r(G)$, $1 \leqq n \leqq r(H), r(G)+1 \leqq u \leqq b(H), r(H)+1 \leqq v \leqq b(G)$. Then $S_{n}$ is in the centre of $K$ and hence $K$ is of class $c+1$ and therefore class $c$. Therefore $K=G \times H$ and $b(K) \leqq \max (b(G)-r(H), 0)+\max (b(H)-r(G), 0)$.

We have inductively that

$$
d\left(G^{k}\right)=k d(G) \text { and } r\left(G^{k}\right)=k r(G)+(k(k-1) / 2) d(G)^{2} .
$$

Also the lemma states that $b\left(G^{2}\right) \leqq 2 b(G)$ and hence $b\left(G^{2 k}\right) \leqq 2^{k} b(G)$. Choose a $k$ such that $b(G) \leqq 2^{k-3} d(G)^{2}$ and consider $G^{2^{k}} \times G^{2^{k}}$. We have,

$$
b\left(G^{2^{k+1}}\right) \leqq 2 \max \left(b\left(G^{2^{k}}\right)-r\left(G^{2^{k}}\right), 0\right),
$$

and since

$$
b\left(G^{2^{k}}\right) \leqq 2^{k} b(G) \leqq 2^{2 k-3} d(G)^{2} \leqq r\left(G^{2^{k}}\right),
$$

then $b\left(G^{2 k+1}\right)=0$.

Let $\alpha$ be such that $b\left(G^{\alpha}\right)=0$ where $\alpha \geqq 2^{k+1}$ then we will show that $b\left(G^{\alpha+1}\right)=0$. We have $r\left(G^{\alpha}\right) \geqq 2^{2 k-3} d(G)^{2}$ and $b(G) \leqq 2^{k-3} d(G)^{2}$ whence by the lemma

$$
\begin{aligned}
b\left(G^{\alpha+1}\right) & \leqq \max (-r(G), 0)+\max \left(b(G)-r\left(G^{\alpha}\right), 0\right) \\
& \leqq \max \left(2^{k-3} d(G)^{2}-2^{2 k-3} d(G)^{2}, 0\right) \\
& \leqq 0, \text { and we have proved the following: }
\end{aligned}
$$

THEOREM. Let $G$ be a finite p-group. Then there exists an integer $n(G)>0$ such that $G^{k} \in \mathscr{G} p$ for all $k \geqq n(G)$.

\section{References}

D. L. Johnson and J. W. Wamsley (1970), 'Minimal relations for certain finite p-groups,' Israel. J. Math. 8, 349-356.

J. W. Wamsley (1972), 'On a class of groups of prime-power order,' Israel J. Math. 11, 297-298.

School of Mathematics

Flinders University

South Australia 